\title{
Laboreal
}

Volume $12 \mathrm{~N}^{\circ} 1$ | 2016

Os Equipamentos de Proteção Individual (EPI):

protetores, mas nem sempre

\section{Maurice Reuchlin e a dialética laboratório / terreno}

Maurice Reuchlin y la dialéctica de laboratorio / campo

Maurice Reuchlin et la dialectique laboratoire / terrain

Maurice Reuchlin and the dialectics lab / field

Jacques Leplat

Tradutor. João Viana Jorge

(2) OpenEdition

Journals

\section{Edição electrónica}

URL: http://journals.openedition.org/laboreal/3362

DOI: $10.4000 /$ laboreal.3362

ISSN: 1646-5237

\section{Editora}

Universidade do Porto

\section{Refêrencia eletrónica}

Jacques Leplat, « Maurice Reuchlin e a dialética laboratório / terreno », Laboreal [Online], Volume 12 N01 | 2016, posto online no dia 01 julho 2016, consultado o 24 setembro 2020. URL : http:// journals.openedition.org/laboreal/3362 ; DOI : https://doi.org/10.4000/laboreal.3362

Este documento foi criado de forma automática no dia 24 setembro 2020.

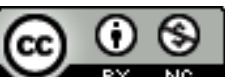

Laboreal está licenciado com uma Licença Creative Commons - Atribuição-NãoComercial 4.0 Internacional. 


\title{
Maurice Reuchlin e a dialética laboratório / terreno
}

\author{
Maurice Reuchlin y la dialéctica de laboratorio / campo \\ Maurice Reuchlin et la dialectique laboratoire / terrain \\ Maurice Reuchlin and the dialectics lab / field
}

Jacques Leplat

Tradução : João Viana Jorge

\section{NOTA DO EDITOR}

http://dx.doi.org/10.15667/laborealxii0116jl

1 A escolha do texto aqui apresentado responde a uma dupla intenção: propor um tema que manteve todo o seu interesse e em seguida render homenagem a um grande psicólogo, Maurice Reuchlin (1920-2015), recentemente falecido após uma longa enfermidade que prematuramente o condenou ao silêncio. Este investigador produziu uma importante obra em livros e artigos. Citemos dela dois exemplos: um Tratado de psicologia, diversas vezes reeditado, e um Tratado de psicologia aplicada (obra coletiva da qual assegurou a direção) que engloba uma dezena de volumes cobrindo os grandes campos da psicologia aplicada. Não se trata aqui de fazer um balanço desses trabalhos, nisso outros se empenharão, mas de propor um texto que se insere bem no período em que foi escrito e num campo do interesse do autor. 0 presente comentário incidirá sobre o próprio texto e sobre o desenvolvimento das ideias que ele defendeu. Far-se-á também alusão a campos de pesquisa que tenham alguma relação com essas ideias e sejam suscetíveis de as enriquecer.

O texto escolhido foi publicado num número do Travail Humain de 1978 (volume 41, fasc. 2, pp. 307-324). Faz parte de um ciclo de estudos organizados no quadro da III $^{\mathrm{a}}$ secção da École Pratique des Hautes Études (EPHE). Os autores dos textos desse ciclo que figuram no mesmo número tinham importantes responsabilidades nos laboratórios 
de psicologia da EPHE agrupados no mesmo edifício e desejavam mostrar, com este ciclo de estudos, que tinham preocupações comuns apesar da diversidade das suas respetivas orientações. 0 tema geral deste ciclo de estudos, «a investigação psicológica em laboratório e no terreno» não tinha sido escolhido ao acaso. Com efeito, nessa mesma época, tinha dado lugar a numerosos debates, nomeadamente no seio da Société française de psychologie que tinha, em 1969, organizado a sua reunião anual com este tema. Para bem situar o contexto no qual se insere o presente texto pareceu útil referir o título e os autores das comunicações apresentadas nesse ciclo, constando, também eles naquele número do Travail Humain.

R. Zazzo - O estudo da criança em laboratório e em situações habituais.

tiot- Alphandéry - A escola é um terreno?

F. Bacher - Os inquéritos: contribuições e limites de um método de estudo no terreno.

J. Leplat - A equivalência das situações em laboratório e de terreno.

7 M. Reuchlin - Uma tentativa de análise da distinção «Psicologia em laboratório Psicologia no terreno».

8 Sobre o tema deste ciclo de estudos encontrar-se-ão ecos em numerosos textos de Reuchlin mencionados na parte que se segue. Há um particularmente típico intitulado «A psicologia aplicada terá métodos próprios?» no capítulo introdutor do tomo 2 do Traité de psychologie appliquée em que este autor assumiu a direção. Notar-se-á também que Reuchlin, no texto aqui referido, modificou um pouco o título usado na apresentação dos trabalhos publicados, «a investigação psicológica em laboratório e no terreno» passou a «... psicologia em laboratório, psicologia no terreno». Não discutiremos esta «tradução» mas quereríamos sublinhar a escolha que fizemos de centrar o nosso comentário na noção de psicologia aplicada que engloba a precedente permitindo situá-la melhor.

9 Uma parte importante da obra de Reuchlin foi consagrada à psicologia aplicada, nomeadamente àquele Tratado do qual redigiu diversos capítulos sendo de lamentar que tenha sido esquecido demasiado depressa. Os dez tomos desse tratado cobrem um largo campo como o seu título testemunha: As aplicações da psicologia. Os métodos da psicologia aplicada. Trabalhadores e sistemas técnicos. Trabalhadores e empregos. A educação e o desenvolvimento individual. As instituições educativas. 0 diagnóstico das deficiências e a reeducação. As aplicações médicas. A psicologia social. A vida quotidiana. Qualquer trabalho sério num destes domínios não pode ignorar estes textos, tendo cada um deles sido objeto de um sério exame crítico. Posso testemunha-lo tendo eu próprio escrito diversos capítulos desse tratado e tendo podido apreciar a qualidade e a abertura com a qual as discussões prévias dos textos tinham sido conduzidas.

O prólogo do primeiro tomo sobre "as aplicações da psicologia» esboça alguns problemas colocados pela conceção de tal obra e justifica as opções tomadas. Aí se encontram alguns ecos das ideias e questões debatidas no texto de referência aqui comentado. A começar, esta declaração que introduz o primeiro parágrafo: «a psicologia aplicada tomando por objeto o homem no seu meio de vida corrente, está diretamente dependente do desenvolvimento geral da sociedade». A seguir, esta declaração à qual teremos de voltar: «o tema mais central é o do próprio estatuto da psicologia aplicada. Alguns tendem a considera-la como a ciência do homem no meio da sua vida habitual; outros como a aplicação de uma ciência psicológica fundamental, 
teórica, pura, experimental; outros ainda como uma prática concreta tornando irrisória qualquer referência à ciência» (p. 6). É também possível distinguir «uma tendência ao interesse pelas diferenças individuais e uma outra orientada para o estudo das condições do meio impostas a todos os indivíduos de um grupo (condições de trabalho, métodos pedagógicos, etc.)»(p.7).

O segundo capitulo deste primeiro tomo intitula-se «Nascimento da psicologia aplicada» e constitui uma espécie de história da psicologia aplicada vista através das correntes teóricas nas quais se inseriram as pesquisas desse período inicial: psicologia funcionalista, psicologia estruturalista, psicologia dinâmica. Para ficar mais perto do tema deste comentário pareceu útil começar por retomar esta noção de psicologia aplicada cujas ambiguidades são a fonte das questões que revelam a dificuldade de delimitar o espaço a dar à psicologia no estudo das situações em que se exercem as atividades humanas. Tratar-se-á em seguida de duas noções suscetíveis de enriquecer o debate próprio ao texto comentado.

\section{A noção de psicologia aplicada}

12 As pesquisas psicológicas sobre situações de trabalho e mais geralmente sobre «o meio de vida habitual», para retomar a expressão de Reuchlin, foram inicialmente categorizadas sob o nome de psicotécnica. Nisso Lahy foi, em França, o grande precursor e produziu, sob esta designação, um grande número de trabalhos. Disso se encontrarão referências nos textos consagrados à história da psicologia do trabalho, nomeadamente num número especial da revista «Psychologie française» consagrado ao centenário da Société française de psychologie e também nos textos de Suzanne Pacaud que publicou individualmente e em colaboração com Lahy numerosos textos sob a designação de psicotécnica e depois sob a de psicologia aplicada. A palavra psicotécnica figura também no nome de instituições onde trabalhavam investigadores psicólogos. Assim, Faverge (1912-1988) coautor com Ombredane (1898-1958) do livro sobre a análise do trabalho (1955), trabalhava num organismo que se chamava "Centre d'Études et Recherches Psychotechniques» (CERP) e pertencia a uma associação profissional dita «Association Professionnelle des psychotechniciens diplomés». Mas numa época em que se desenvolvia a formação de psicólogos do trabalho o termo psicotécnico tinha má fama em virtude do termo "técnico" ser julgado desvalorizador pelos interessados. Apareceu então e generalizou-se a denominação de psicologia aplicada. Mas esta, por sua vez, veio também a revelar-se insatisfatória. O próprio Lahy (1932) referia que «agora que a psicologia dita aplicada ultrapassou o período das primeiras aplicações podemos colocar em toda a sua extensão o problema dos seus fundamentos» (Lahy, 1932, p. 11). Citemos entre esses: «A psicologia dita aplicada é "exclusivamente" aplicada ou deve-se considera-la como a psicologia geral, simultaneamente teórica e aplicada?» (id.).

Wallon (1930/1946) por sua vez denunciou as ambiguidades e interpretações incorretas da denominação de psicologia aplicada. «A psicologia aplicada não consiste em fazer passar ao domínio das aplicações práticas os princípios ou verdades da psicologia que se diz teórica, racional, ou que se fundamenta muito simplesmente na introspeção» (Wallon, 1930/1946, p. 7). Com efeito, a palavra aplicação veicula com ela a ideia de que existe um corpus de conhecimentos diretamente exploráveis para a conceção de uma intervenção. Ora esta ideia é contestável. Se é verdade que uma intervenção apela a conhecimentos anteriores é antes do mais necessário determinar aqueles a que é 
preciso apelar: antes da aplicação insere-se portanto uma fase de análise requerendo ela própria conhecimentos prévios. As pesquisas ergonómicas iam justamente pôr em evidência a importância desta etapa prévia que seria designada por etapa do diagnóstico, prévia à postura em prática ou à elaboração dos conhecimentos que orientarão a intervenção. A obra de Guérin e colaboradores (1997) apresentou particularmente bem e ilustrou este lugar do diagnóstico na démarche ergonómica.

É importante assinalar uma possibilidade de deriva no uso da noção de aplicação, deriva que era frequente nos meios universitários na altura do desenvolvimento da psicologia ergonómica mas talvez disso ainda se encontrem vestígios na atualidade. Essa deriva caracteriza-se pela opinião de que qualquer pesquisa no terreno, quer dizer nas condições de vida e de trabalho habituais é uma pesquisa aplicada: houve um tempo em que esta opinião era corrente e difícil de combater.

Tínhamos publicado nessa época (1982), que era também a do desenvolvimento da psicologia cognitiva, um artigo intitulado «0 terreno, estimulante (ou obstáculo) do desenvolvimento da psicologia cognitiva». Esse texto tinha levado a definir com precisão as características das situações de terreno relativamente às situações de laboratório e ao mesmo tempo a mostrar a necessidade de articular as pesquisas conduzidas nos dois domínios. Na conclusão referia-se: «assim, não se falará de psicologia de terreno nem de psicologia em laboratório, como se existissem duas psicologias distintas. 0 terreno e o laboratório são simplesmente dois lugares onde, de forma coordenada, deveria ser elaborada a psicologia» (p. 127). Um outro interesse desse texto era o de estar semeado com comentários críticos detalhados de investigadores franceses e estrangeiros que lhes tinham sido solicitados, comentários esses que enriqueciam assim o debate respeitante aos dois termos terreno/laboratório e suas relações.

16 A questão então debatida continuou a sê-lo nos anos seguintes nomeadamente no domínio da didática profissional. Existe uma obra particularmente clara e documentada de Pastré (2011), «La didactique professionnelle» (subtítulos: abordagem antropológica do desenvolvimento nos adultos. Formação e prática profissionais) à qual teremos de voltar.

\section{O papel do contexto}

17 A análise das situações de trabalho no terreno faz surgir o importante papel desempenhado pelo contexto. Leplat $(2002,2006)$ consagrou a este tema duas importantes revisões sugerindo uma abundante bibliografia que clamaria por ser atualizada mas que fornecia já os elementos essenciais à conceção duma pesquisa sobre o tema ou, mais simplesmente, para ter em conta o papel desta característica ligada a qualquer situação prática ou de trabalho. Hollnagel (1993) tinha desenvolvido um modelo de controlo da ação pelo contexto a partir da ideia de que «as ações só são significativas num contexto» (p.164) e que o contexto pode guiar a execução da ação. A noção de contexto está muito ligada ao problema da possibilidade de generalização dos resultados de um estudo incidente numa atividade a um incidente numa outra atividade admitida como semelhante. É um caso que se encontra particularmente em situações não construídas pelo analista e está no cerne nomeadamente do problema da validade ecológica. Se as relações do contexto com a comunicação foram talvez menos diretamente estudadas, não é menos verdade que «o contexto é uma componente 
essencial da comunicação e uma fonte major de simplicidade e de eficiência» (Brown e Duguid, 1994, p. 3). Sendo as palavras «contexto» e «comunicação» polissémicas deveriam sempre ser bem definidas e estudadas conjuntamente. As pesquisas mostram que, se o contexto desempenha um papel de meio e de modulador do sentido das comunicações, pode também ter nelas efeitos parasitas. As pesquisas sugerem em todo o caso que comunicação e contexto devem ser sempre estudadas conjuntamente, nomeadamente a fim de melhor definir a atividade efetiva e a sua conceção.

\section{A simulação}

Os problemas colocados pelas relações entre o laboratório e o terreno são muito próximas das encontradas pela simulação como instrumento de formação. Estes problemas tornaram-se crescentemente notórios em virtude do acréscimo da complexidade dos sistemas técnicos e das suas consequências na complexidade dos empregos e da correspondente formação. $O$ exame das relações entre situação de laboratório e situação no terreno não pode deixar de evocar o exame das relações entre a situação a simular e a sua simulação: são os mesmos tipos de problemas que se levantam nos dois casos. Consideremos aqui a formação: a questão fundamental que se coloca ao formador que pretende explorar a simulação é a de conceber um simulador que facilite a aprendizagem da tarefa que terá de ser posteriormente executada. Para isso não é evidentemente suficiente construir um simulador que imite simplesmente a aparência da tarefa a aprender. Essa fidelidade facial não é desinteressante mas é completamente insuficiente quando se trata de uma tarefa complexa. 0 simulador deve permitir ao aprendiz adquirir a competência desejada o que não poderá ser atingido senão com um simulador que prepare para a aquisição dos mecanismos da atividade mesmo que por vezes o seja com um simulador que não se pareça visualmente com a tarefa simulada. A literatura sobre estes assuntos é atualmente abundante e de qualidade muito diversificada: não se pode mais do que aludir a este ponto.

Uma obra coletiva de Bainbridge e Ruiz Quintanilla (1989) tem toda uma parte centrada sobre peritagem e a simulação como instrumento de formação: apresenta em detalhe os quadros de análise, uma metodologia e exemplos oriundos do domínio industrial. Sublinha a importância da análise prévia da atividade na elaboração de uma simulação tendo em vista a formação. Mais recentemente Fauquet-Alekhine e Pehuet (2011) apresentaram um livro consagrado, também ele, à «melhoria das práticas profissionais por via da simulação», livro esse concebido com a colaboração direta de especialistas na formação que tinham seguido a conceção e a exploração no terreno do dispositivo por eles proposto. Por fim merece ser assinalada a obra de Pastré (2011), já antes citada, que inclui um capítulo intitulado "Os dispositivos de aprendizagem construídos» no qual são propostos métodos de análise permitindo planificar a conceção de simuladores. Propõe e comenta diversos exemplos nos quais participou diretamente: por exemplo um simulador de resolução de problemas incidindo na regulação de uma prensa de injeção de plásticos (p. 269), um dispositivo de simulação da poda da vinha (p.273). o comentário destes casos é muito instrutivo e constitui uma boa iniciação metodológica apropriada para interessar os formadores. 


\section{Conclusão}

O tema do ciclo de estudos no qual se inscreve a síntese apresentada por Reuchlin é bem revelador, na sua própria formulação, das preocupações dos psicólogos no momento em que foi escrita. Nessa época subsistiam ainda traços dos vivos debates de 1968 sobre o alcance prático das pesquisas de laboratório tal como sobre o significado do resultado dessas pesquisas para os indivíduos e a sociedade. Tinham sido conduzidos debates sobre as relações entre as pesquisas levadas a cabo naqueles dois lugares mas era mais sobre a articulação e os objetos dessas pesquisas que sobre os respetivos locais de realização que o foco devia incidir. Esses debates iam fazer emergir um certo número de distinções que continuarão ainda por longo tempo a suscitar o interesse e o debate no seio de psicólogos de várias especialidades. As expressões de "psicologia aplicada» como a de "acoplamento ou dialética laboratório/terreno» não são para tomar à letra mas como designando um conteúdo a explicitar permanentemente. Reuchlin terá trazido uma importante contribuição ao que se poderia designar mais geralmente como as relações entre a teoria e a prática mas há ainda muito a fazer pela psicologia nesse campo, não esquecendo a finalidade da pesquisa e as suas relações com o contexto e outras disciplinas suscetíveis de estarem implicadas.

\section{BIBLIOGRAFIA}

Bainbridge, L., \& Ruiz Quintanilla S.A. (Eds.) (1989). Developing skills with information technology, Chichester, UK : Wiley.

Brown, J.S. \& Duguid, P. (1994). Borderlines issues: social and material aspects of design. HumanComputer Interaction, 9, 3-36.

Fauquet-Alekhine, P. \& Pehuet, N. (2011). Améliorer les pratiques professionnelles par la simulation. Toulouse : Octares. Version anglaise : Simulation Training : Fundamentals and Applications. Springer International Publishing AG Switzerland.

Guérin, F., Laville, A., Dianellou, F., Duraffourg, J. \& Kerguelen, A. (1997). Comprendre le travail pour le transformer : la pratique de l'ergonomie. Montrouge : ANACT.

Hollnagel, E. (1993). Human reliability analysis. Context and control. London : Academic Press.

Lahy, J.-M. (1932). Les fondements scientifiques de la psychotechnique. L'hygiène Mentale, 27, 10, 273-302. (Un extrait de cet article figure dans un numéro spécial sur le centenaire de la société de psychologie française de la revue Psychologie française, Mars 2000, 45, 1, 273-277).

Leplat, J. (1982). Le terrain, stimulant (ou obstacle) au développement de la psychologie cognitive. Cahiers de psychologie cognitive, 2, 2, 115-130.

Leplat, J. (2001). La gestion des communications par le contexte, Perspectives interdisciplinaires sur le travail et la santé. Pistes, 3-1.

Leplat, J. (2006). Les contextes en formation. Éducation permanente, 166, 1, 29-48. 
Ombredane, A. \& Faverge, J.-M. (1955). L'analyse du travail. Paris : PUF.

Pastré, P. (2011). La didactique professionnelle. Approche anthropologique du développement chez les adultes. Formation et pratiques professionnelles. Paris : PUF.

Reuchlin, M. (1973). La psychologie appliquée a-t-elle des méthodes propres ? Dans M. Reuchlin (s/d). Traité de psychologie appliquée, tome 2. Méthodes (p. 5-18). Paris : PUF.

Reuchlin, M . (1977). Psychologie. Paris : PUF. ( $4^{\circ}$ éd.).

Wallon, H. (1930/1946). Principes de psychologie appliquée. Paris : A. Colin.

\section{AUTORES}

\section{JACQUES LEPLAT}

Groupe de Recherche et d'Etude sur l'Histoire du Travail et de L'Orientation (GRESHTO)

Centre de Recherche sur le Travail et le Développement (CRTD)

Conservatoire National des Arts et Métiers (CNAM)

41, Rue Gay Lussac 75005 Paris

France

jacques.leplat@wanadoo.fr 